\title{
Study on static lateral load-slip behavior of single-shear stapled connections in plywood for upholstered furniture frame construction
}

\author{
Wengang $\mathrm{Hu}^{1,3^{*}}$ (1) and Jilei Zhang ${ }^{2}$
}

\begin{abstract}
The static lateral load-slip behavior of a single-shear plywood-to-plywood single-staple connection (SPSC) was investigated experimentally. A mechanics-based approach was used to develop mechanical models for deriving estimation equations for critical lateral loads of SPSCs based on failure modes of staple legs and connection member materials developed during static lateral loading process. Experimental results indicated that the static lateral load-slip behavior of SPSCs can be characterized with three major stages. This experiment provided the evidence that the ultimate lateral load capacity of SPSCS was partially governed by staple direct withdrawal load capacity in main members. The proposed mechanical models were verified experimentally as a valid means for deriving estimation equations for critical lateral loads of SPSCs evaluated in this study.
\end{abstract}

Keywords: Lateral load, Stapled connection, Plywood, Upholstered furniture frame construction

\section{Introduction}

Furniture is an important item used in our daily life for millenniums, form traditional lacquer furniture [1] to modern intelligent furniture [2], which makes our life comfortable and efficient. Benefiting from natural fiber and wood-based materials [3-8], new types of furniture are designed and manufactured. Meanwhile, new engineering issues also emerged.

Staple is a mechanical fastener commonly used in upholstered furniture frame construction, rapidly connecting frame structural members of wood-based panel composites like plywood and oriented strand board (OSB) together to form various configurations of stapled connections. The strength design of connections in upholstered furniture frames is one of the most important steps considered in the entire engineering design process because most structural failures occur at

\footnotetext{
*Correspondence: hwg@njfu.edu.cn

${ }^{1}$ Co-Innovation Center of Efficient Processing and Utilization of Forest Resources, Nanjing Forestry University, Nanjing 210037, China

Full list of author information is available at the end of the article
}

connections [9-13]. As a mechanical fastener, a staple is a critical connection commonly subject to either a lateral shear force only, or a direct withdrawal force only, or both forces at the same time [14-17]. Therefore, knowing the various load capacities of a single-shear stapled connection, especially the static lateral load, can provide fundamental information in assisting the strength design of upholstered furniture frame construction connected with staples.

Previous studies related to the lateral load of singleshear stapled connections [16-21] usually used the regression approach to derive the functional relationship between the lateral load and various factors.

Zhang et al. [14-16] studied direct withdrawal and face lateral load resistance of single and multi-staple joints in pine plywood through experimental tests. Yadama et al. $[17,18]$ investigated effects of the number and spacing between staples as well as the staple leg penetration on withdrawal and lateral resistance of stapled joints in wood (Eastern cottonwood, red oak, yellow poplar, sweetgum) and wood-based materials (MDF, OSB). The results showed that staple joints with higher density 
members provided the most resistance to withdrawal and lateral loads, number of staples and leg penetration positively affected the joint resistance. Meanwhile, onerow and two-row staples on face lateral load resistance of staple joints in OSB were also studied by Demirel et al. [19-21]. The results indicated that for one-row staple, the lateral shear load resistance capacity of multi-staple joints increased significantly as the number of staples increased from two to four in increments of one. And for two-row staple, Vertical and horizontal staple alignment was found to have no significant effect on the ultimate lateral resistance of the face-to-face OSB joints when the number of staples used was less than eight. Erdil et al. [22] reported that staple holding strength from face was at least $50 \%$ percent higher than that from edge of plywood and OSB. Besides, Genchev et al. [23] and Staneva et al. [24] analyzed the deformation behavior of staple corner joint for upholstered furniture using finite element method (FEM), the rotation stiffness and bending moments of joints were evaluated which will help the design of upholstered furniture.

However, limited studies were found in related to evaluating and modeling the lateral load of single-shear stapled connections in wood-based composites based on the European Yield Model (EYM) of Johansen [25] using a mechanics-based approach with certain assumptions. Main factors related to basic material mechanical properties in the mechanics-based approach are dowel-bearing strengths in connection member materials, dowel-bending strengths, etc.

In Wood Handbook [26], the lateral load of bright common wire nails driven into the side grain of seasoned wood is expressed by the empirical equation $P=K D^{3 / 2}$, i.e., $P$ is the lateral load, $K$ is a coefficient, and $D$ is the nail diameter. In addition, the EYM was implied to predict the lateral load. These equations had been recommended to be used in staple connection. However, the axial force transmitted along the length of the fastener was not taken into account in these equations. Eshaghi [27] studied the lateral load of screw connections in medium density fiberboard and particleboard using EYM method. For two-member joints with both members of the same wood bearing strength, Aune and Malloty [28] estimated the ultimate lateral load of single-shear connections constructed with the same material for side and main members using the equation: $F_{\mathrm{u}-\text { Aune }}=\sqrt{2 q_{\mathrm{u}} M_{\mathrm{y}}}$, where $q_{\mathrm{u}}$ is dowel-bearing unit loads at ultimate point, and $M_{\mathrm{y}}$ is bending moment at yield point. In addition, Eurocode 5 [29] indicates that the load-carrying capacity for nails, staples, bolts, dowels, and screws per shear plane per fastener, should be calculated using the expression: $F_{\mathrm{u}-\text { Eurocode }}=1.15 \sqrt{2 f_{\mathrm{em}, \mathrm{y}} d M_{\mathrm{y}}}+f_{\mathrm{u}} / 4$, where $f_{\mathrm{em}, \mathrm{y}}$ is the dowel-bearing strength at yield point, $d$ is the dowel diameter, $M_{\mathrm{y}}$ is the dowel bending moment at yield point, and $f_{\mathrm{u}}$ is the direct withdrawal load.

In summary, there was no specific mechanical model studied for estimating the ultimate lateral load of singleshear stapled connection in wood-based composites. Current yield models and equations just focus on the yield load or ultimate load of bolt, screw and nail connections. The hypothesis of this study was that the shape of a deformed staple leg in single-shear composite-to-composite single-staple connections could be different from the general assumed yield modes depicted in current literatures $[25,26]$. Therefore, a new staple mechanical mode might be proposed for the derivation of the equations for predicting the critical lateral loads of a singleshear composite-to-composite single-staple connection based on experimental data.

The main objective of this study was to investigate the static lateral load-slip behavior of a single-shear plywood-to-plywood single-staple connection (SPSC) using the mechanics-based approach. The specific objectives were to (1) evaluate single staple leg-bearing strengths in plywood; (2) evaluate bending properties of single staple legs; (3) evaluate the direct withdrawal load of a single staple in plywood; (4) characterize the lateral load-slip behavior and failure mode of SPSCs; (5) propose mechanical models; (6) derive equations based on proposed mechanical models for the predication of critical lateral loads of SPSCs at different loading stages; and (7) validate mechanical models in terms of the staple deformation and derived predication equations experimentally.

\section{Materials and methods \\ Materials}

One type of 18 -mm-thick, six-ply southern yellow pine plywood purchased from East Mississippi lumber, Mississippi, USA was used in this study. The full-size plywood panel $(1220$ by $2440 \mathrm{~mm}$ ) was constructed with the first, third, and sixth plies (Fig. 1a) with their grain orientation aligned parallel to the panel $2440 \mathrm{~mm}$ direction and the second, fourth, and fifth plies with their grain orientation aligned perpendicular to the panel $2440 \mathrm{~mm}$ direction. The staples used in this study were SENCO 16-gauge galvanized chisel-end-point type made of carbon steel with a crown nominal width of $11.11 \mathrm{~mm}$ and a leg nominal length of $38 \mathrm{~mm}$ (Fig. 1b). The nominal leg width of the staples was $1.575 \mathrm{~mm}$, thickness was $1.397 \mathrm{~mm}$ and equivalent diameter was $1.483 \mathrm{~mm}$.

\section{Experimental design Staple connections}

Figure 2 shows the general configuration of a SPSC used in this study to evaluate its load-slip behavior when it was subjected to a static lateral load. The SPSC consisted 


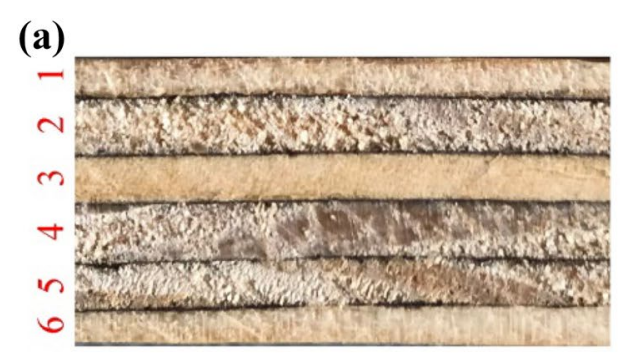

(b)

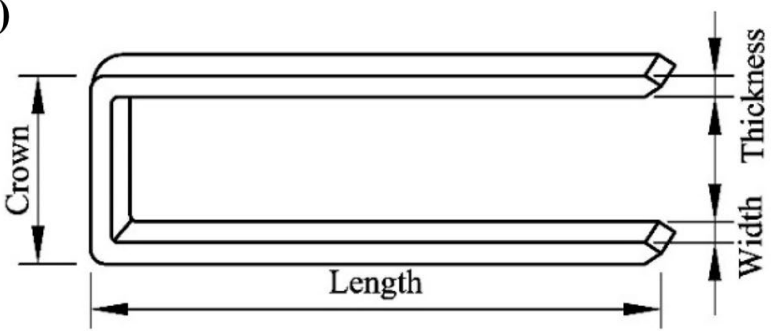

Fig. 1 Picture (a) and diagram (b) showing different orientations of plies in plywood and detailed dimensions of staples used in this study, respectively

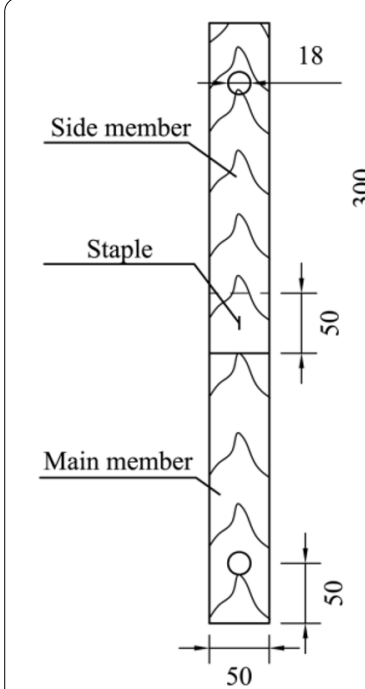

(a)

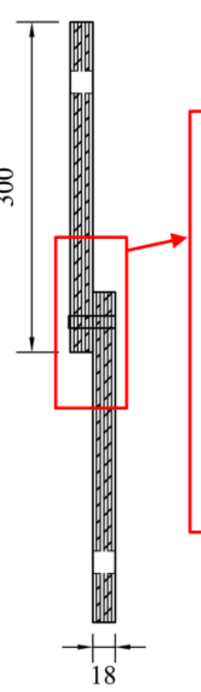

(b)

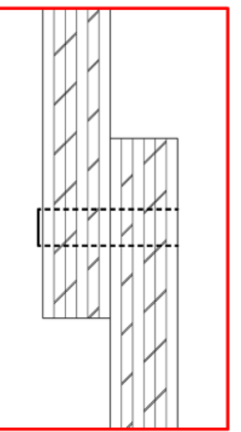

(c)
Fig. 2 The general configuration of a single-shear plywood-to-plywood single-staple connection $\mathbf{a}$ front view, $\mathbf{b}$ side view, and c enlarged diagram showing details at the connection (unit: $\mathrm{mm}$ )

of a plywood main member with its first ply contacted and attached to the first ply of a plywood side member by a single staple driven through the face of the side member into the face of the main member with staple crown oriented in the direction parallel to the face grain orientation of both main and side members and staple legs perpendicular to faces of side member and main member. Both main and side members had nominal dimensions of $300 \mathrm{~mm}$ long $\times 50 \mathrm{~mm}$ wide $\times 18 \mathrm{~mm}$ thick. 20 SPSCs were tested in this experiment.

\section{Basic material properties}

Figure 3 shows the general configuration of a half-hole test block used for evaluating single staple leg-bearing strengths in plywood parallel to its face grain orientation.

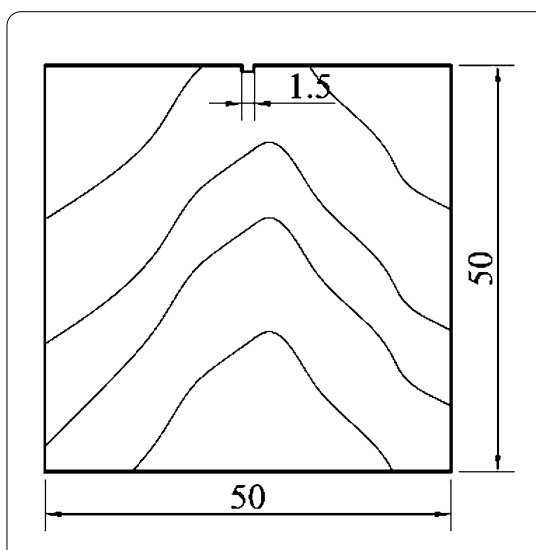

(a)

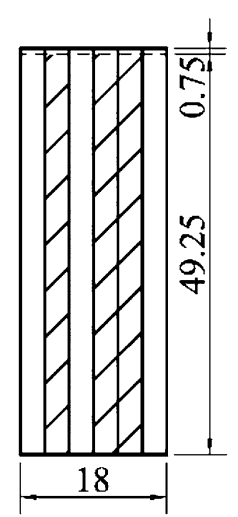

(b)
Fig. 3 The general configuration of a half-hole block for evaluating single staple leg-bearing strength in pine plywood $\mathbf{a}$ front view, $\mathbf{b}$ side view (unit: $\mathrm{mm}$ )

20 replicates were tested according to ASTM D5764-97 [30]. Bending properties of 20 randomly selected single staple legs were measured according to ASTM F157517 [31]. Figure 4 shows the general configuration of a load-test block connection used to evaluate the direct withdrawal load of a single staple in pine plywood perpendicular to the face of a tested block. There were 15 replicates tested. The specific gravity (SG) and moisture content (MC) of 15 blocks cut from SPSC main members, withdrawal tested blocks, and half-hole test blocks were determined according to ASTM D2395-93 [32] and ASTM D4442-92 [33], respectively.

\section{Specimen preparation and testing}

All SPSC members, withdrawal test blocks, and half-hole test blocks were cut from full-size (1220 by $2440 \mathrm{~mm})$ six-ply southern yellow pine plywood panels. Before connections assembly and half-hole fabrication on bearing test blocks, all connection members and test blocks were conditioned in a humidity chamber controlled at 


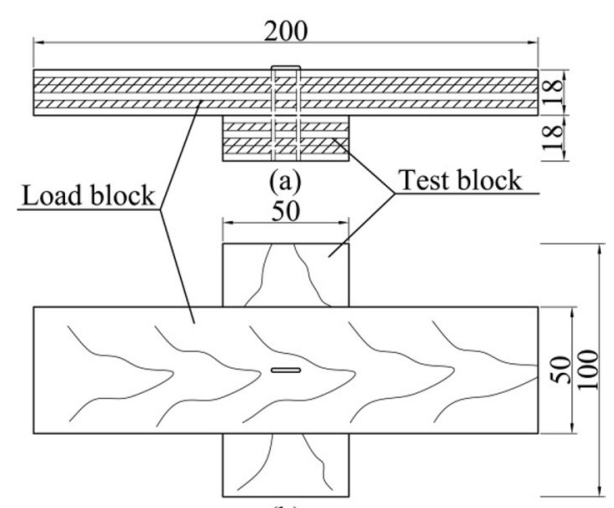

(b)

Fig. 4 The general configuration of a load-test block connection used for evaluating the direct withdrawal load of a single staple from a tested plywood block $\mathbf{a}$ front view, $\mathbf{b}$ top view (unit: $\mathrm{mm}$ )

$20 \pm 2{ }^{\circ} \mathrm{C}$ and $50 \pm 5 \%$ relative humidity (RH) for 2 weeks. The staples were driven into laterally loaded connection members and directly loaded connection blocks with a pneumatic power-driven staple gun with its pressure set to $483 \mathrm{kPa}$. Staple crown uniform contact with the plywood surface ply was attempted. All tests were performed immediately after stapling operation was completed according to ASTM D5764-97 [30].

All single staple leg-bearing, staple-bending, staple direct withdrawal and SPSC tests were performed on an INSTRON universal testing machine (Norwood, MA, USA). Figure 5 shows the setup for evaluating the lateral load-slip behavior of SPSCs. The loading speed was $2.5 \mathrm{~mm} / \mathrm{min}$ in reference to ASTM D1761 [34]. A linear variable differential transformer (LVDT) was attached to each main member of a tested SPSC through a bracket to measure connection slip during lateral loading test. Lateral load-slip curves and failure modes of all tested staple connections were recorded. Additional five connections after tested to their corresponding preset load levels were sliced along staple leg orientation to observe failure modes in terms of the shapes of deformed staple legs and if plywood material crushed underneath staple legs occurred at that load levels.

Figure 6 shows the setup for measuring the half-hole single staple leg-bearing strength in pine plywood test blocks. A specifically designed and fabricated loading head measured $1.575 \mathrm{~mm}$ thick $\times 30 \mathrm{~mm}$ wide $\times 80 \mathrm{~mm}$ high, i.e., the loading head thickness was equal to the width of a staple leg (Fig. 1b), was compressed a halfhole test block at a constant loading speed of $2.5 \mathrm{~mm} /$ min. Bearing load-deformation curves were recorded for all tested blocks. A yield load point was determined through fitting a straight line to a linear portion of the

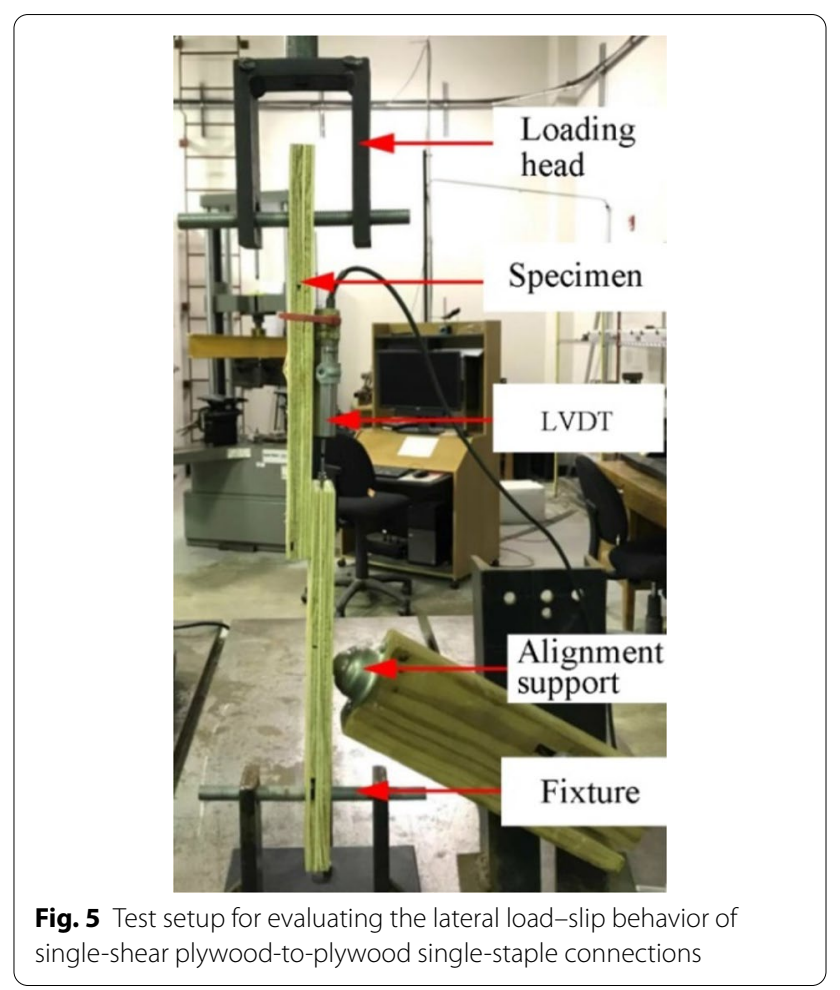

load-deformation curve and offsetting this line by a deformation equal to $5 \%$ of the staple leg width.

The critical single staple leg-bearing strengths in pine plywood $F_{\text {em, pl }}$ at proportional limit, $F_{\text {em, } y}$ at yield point, and $F_{\text {em, u }}$ at ultimate point $(\mathrm{MPa})$ were calculated using the following equation (Eq. 1):

$$
F_{\mathrm{em}}=P / w t,
$$

where $P$ is the compressive load at each critical point as determined from load-deformation curves recorded for

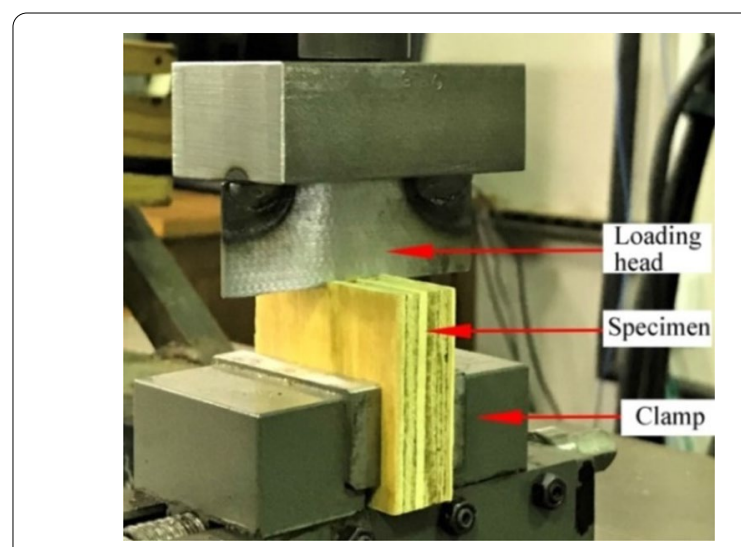

Fig. 6 Test setup for evaluating the load-deformation behavior of single staple legs bearing in half-hole pine plywood test blocks 


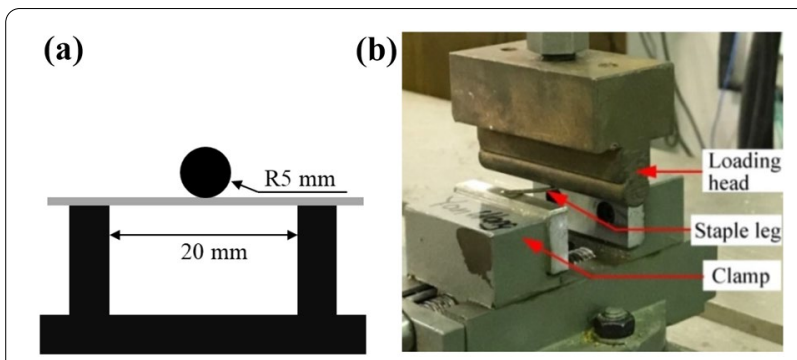

Fig. 7 Setup for evaluating the load-deflection behavior of single legs subjected to a center-loading: $\mathbf{a}$ detail dimensions and $\mathbf{b}$ actual setup

all tested blocks $(\mathrm{N}) ; w$ is the staple leg width $(\mathrm{mm})$, and $t$ is the thickness of a plywood block ( $\mathrm{mm})$.

The corresponding critical single staple leg-bearing unit loads $q_{\mathrm{pl}}$ at proportional limit, $q_{\mathrm{y}}$ at yield point, and $q_{\mathrm{u}}$ at ultimate point $(\mathrm{N} / \mathrm{mm})$ were calculated using the following equation (Eq. 2):

$$
q=F_{\mathrm{em}} w .
$$

Figure 7 shows the setup for determining critical bending moments of single staple legs used in this experiment. The center-loading bending test at a constant loading speed of $2.5 \mathrm{~mm} / \mathrm{min}$ was performed with a span of $20 \mathrm{~mm}$. The critical bending moments $M_{\mathrm{pl}}$ at proportional limit, $M_{\mathrm{y}}$ at yield point, and $M_{\mathrm{u}}$ at ultimate point $(\mathrm{N} \mathrm{mm})$ were calculated using the following equation (Eq. 3) [31]:

$$
M=P_{\mathrm{b}} S_{\mathrm{bp}} / 4,
$$

where $P_{\mathrm{b}}$ is the test bending load at each critical point as determined from load-deflection curves $(\mathrm{N}) ; S_{\mathrm{bp}}$ is the $\operatorname{span}(\mathrm{mm})$.

Staple single-leg bending load-deflection curves were recorded for all tested staple legs. A yield load point was determined through fitting a straight line to a linear portion of the load-deflection curve and offsetting this line by a deflection equal to $5 \%$ of the staple leg width.

Figure 8 shows the setup for evaluating ultimate direct withdrawal loads of single staples from pine plywood test blocks. The loading speed was $2.5 \mathrm{~mm} / \mathrm{min}$ [34].

\section{Results and discussion}

\section{Basic physical and mechanical properties}

Pine plywood SG averaged 0.60 with a coefficient of variation (COV) of $2.8 \%$, while corresponding $\mathrm{MC}$ averaged $8.2 \%$ with a COV of $5.9 \%$. Figure $9 \mathrm{a}$ is a typical loaddeformation curve of single staple leg-bearing in halfhole pine plywood test blocks. The mean values of critical single staple leg-bearing strengths $F_{\mathrm{em}, \mathrm{p}}, F_{\mathrm{em}, \mathrm{y}}$, and $F_{\mathrm{em}, \mathrm{u}}$ with their COV values are $45.64(8.0 \%), 54.6(12.8 \%)$, and

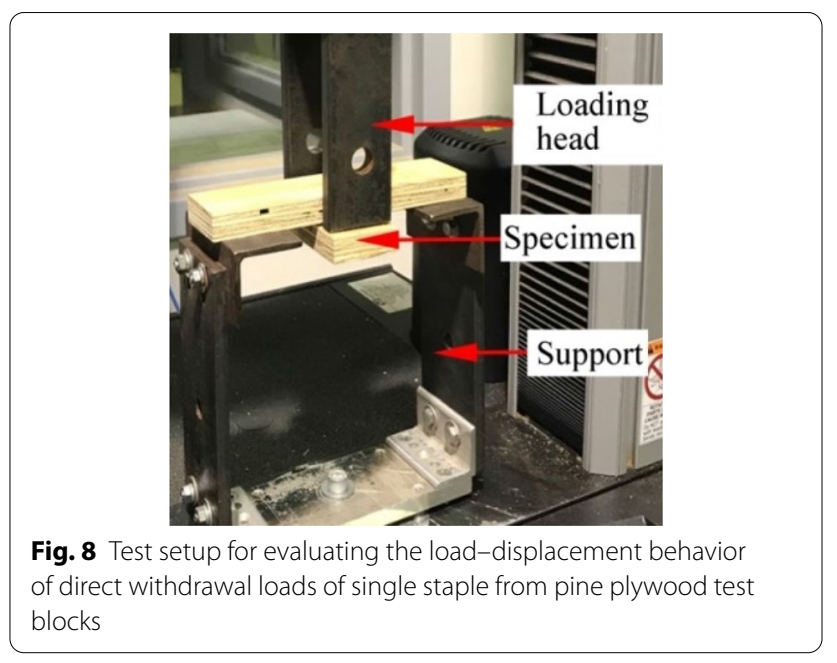

$131.2(12.4 \%) \mathrm{N} / \mathrm{mm}^{2}$, respectively. The corresponding mean values of critical single staple leg-bearing unit loads $q_{\mathrm{p}}, q_{\mathrm{y}}$, and $q_{\mathrm{u}}$ were calculated using Eq. (2) and summarized in Table 2. Figure 9b shows a typical load-deflection curve of single staple leg-bending tests. The mean values of critical bending moments of single staple legs are summarized in Table 1. Figure 9c is a typical loaddisplacement curve of direct withdrawal of single staples from test pine plywood blocks. The mean value of ultimate direct withdrawal load, $f_{\mathrm{u}}$, of single staples in pine plywood is summarized in Table 1 .

\section{Staple joint \\ Load-slip curve and failure modes}

Figure 10 is a typical load-slip curve of SPSCs when subjected to a static lateral load, having three different stages. Stage 1 is the first linear-yield portion, starting from 0 up to passing the first yield point, $F_{\mathrm{y}-1}$, and reaching the end of the first yield portion. The linear portion in this stage was because compressed plywood materials underneath and above staple legs in side member were still in their elastic region and there was no obvious sign of staple legs being bent (Fig. 11a) in both main and side members as the lateral load increased from 0 to the first proportional limit point, $F_{\mathrm{pl}-1}$. The mean lateral load at the first proportional limit point (with its COV) of SPSCs was $329.8 \mathrm{~N}(12.9 \%)$. The first yield portion started at the first proportional limit point, $F_{\mathrm{pl}-1}$, up to the starting point of the second linear-yield curve, where the yield portion was mainly because of staple legs in both side and main members having a slight one-point bent (Fig. 11b), i.e., one plastic hinge of staple legs was developed in both main and side members, rather than fractured plywood materials because there was not any obvious compressive fracture occurred at plywood materials contacting to 

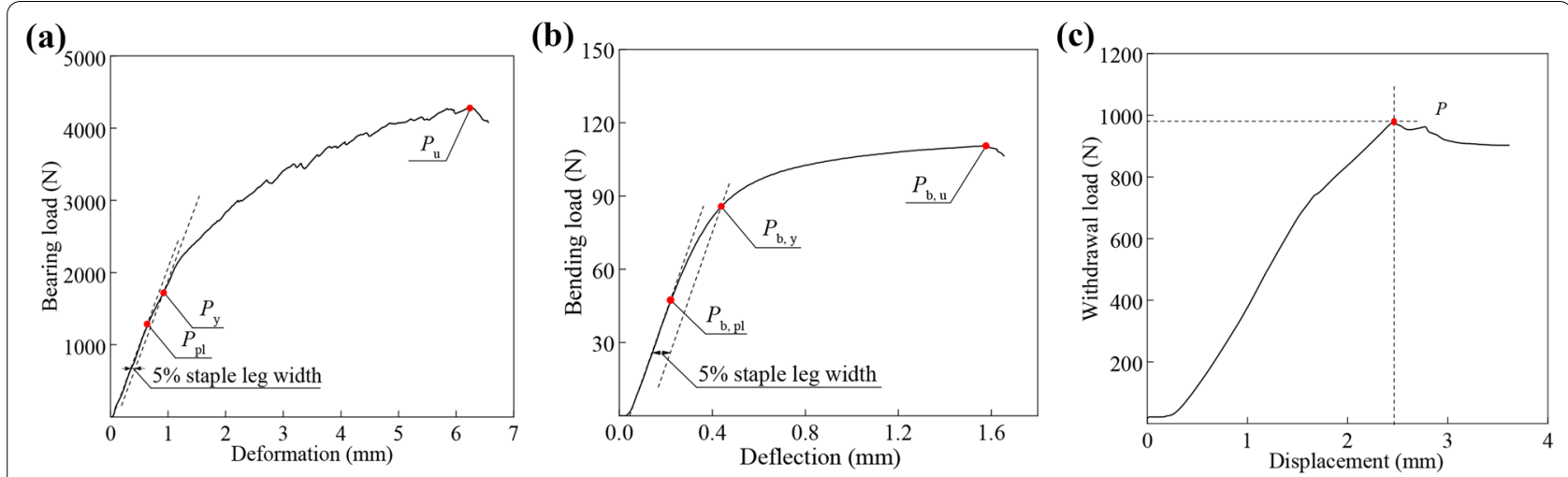

Fig. 9 Typical curves of: a bearing load-deformation of single staple legs tested in half-hole pine plywood test blocks; $\mathbf{b}$ load-deflection of single staple legs subjected to center-bending loading; c load-displacement of direct withdrawal of a single staple from pine plywood test blocks

Table 1 Summarizes mean values of mechanical properties of tested plywood and staple legs

\begin{tabular}{|c|c|c|c|}
\hline Critical point & $\begin{array}{l}\text { Staple leg-bearing unit load (N/ } \\
\mathrm{mm} \text { ) }\end{array}$ & $\begin{array}{l}\text { Single staple leg bending moment } \\
(\mathrm{N} \mathrm{mm})\end{array}$ & Staple withdrawal load (N) \\
\hline Proportional limit & $a_{\mathrm{pl}}=71.89(8.0)$ & $M_{\mathrm{pl}}=229.5(10.8)$ & $\mathrm{n} / \mathrm{a}$ \\
\hline \multirow[t]{2}{*}{ Yield } & $q_{y}=85.95(12.8)$ & $M_{y}=353.7(5.6)$ & $\mathrm{n} / \mathrm{a}$ \\
\hline & & & $\mathrm{n} / \mathrm{a}$ \\
\hline Ultimate & $q_{u}=206.60(12.4)$ & $M_{\mathrm{u}}=540.8(4.1)$ & $f_{u}=889.7(13.7)$ \\
\hline
\end{tabular}

Values in parentheses are coefficients of variation in percentage

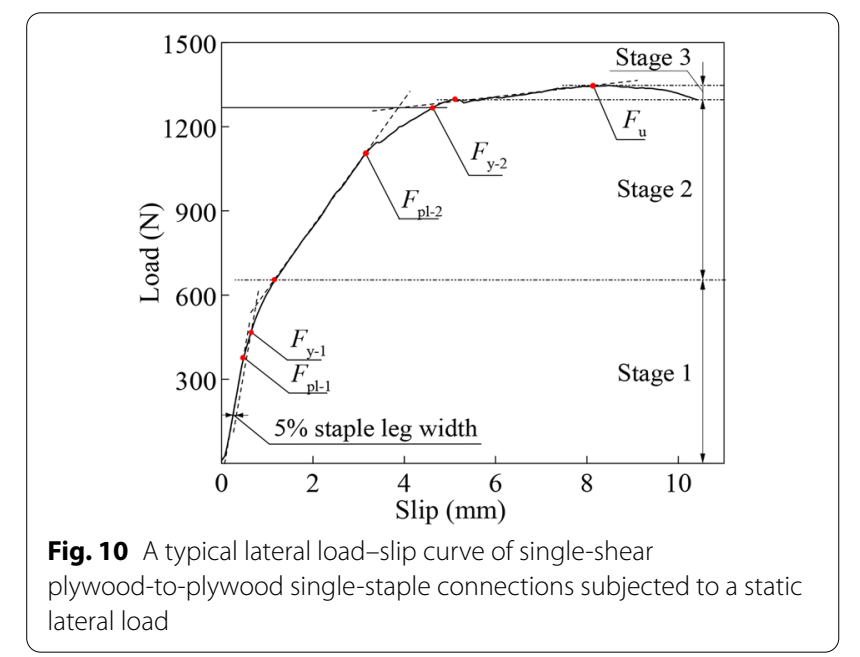

staple legs, and materials underneath staple legs in side member and above staple legs in main member were still in their elastic region, but there is a possibility that the plywood material at the connecting point of side and main member above the staple leg reaching its material yield point. The mean lateral load at the first yield point, $F_{\mathrm{y}-1}$, (with its COV) of SPSCs evaluated was $363.36 \mathrm{~N}$ $(12.5 \%)$, and this lateral load value was obtained through offsetting the straight load-slip line by a slip equal to $5 \%$ of the staple leg width.

Stage 2 is the second linear-yield portion, starting from the end of first yield curve, passing the second yield point, $F_{\mathrm{y}-2}$, and reaching the end of the second yield curve. The second yield point was the interception point of two straight lines (Fig. 10) obtained through drawing an extension line of the straight line in the Stage 2 and also a tangential line of the load-slip curve of Stage 3 [16]. In this stage, plywood materials underneath staple legs in side member and above staple legs in main member had their deformation transiting from elastic to plastic, i.e., plywood materials started its yielding process and the regions close to two member contacting sides were in their plastic regions as the lateral load increased to $F_{\mathrm{pl}-2}$ (Fig. 11c), and further increasing the lateral load beyond the second yield point compressively fractured plywood materials underneath staple legs in side member and above staple legs in main member and staple legs continued their one plastic hinge bending process, but no staple leg withdrawing was observed (Fig. 11d). The mean lateral load at the second proportional limit point, $F_{\mathrm{pl}-2}$, and second yield point, $F_{\mathrm{y}-2}$ (with their COVs) of evaluated SPSCs were $903.6(11.1 \%)$ and $1056(11.7 \%) \mathrm{N}$, respectively. 

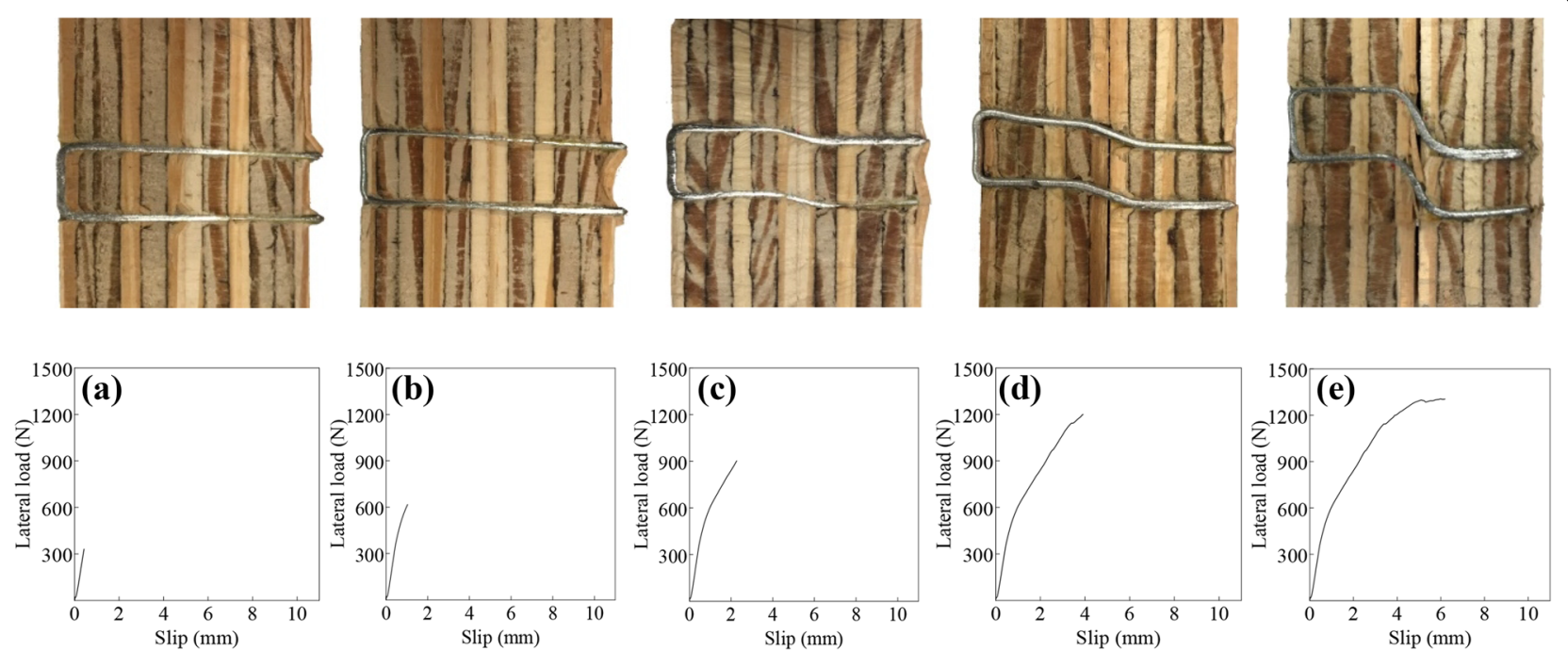

Fig. 11 Images showing single staple connection failure modes in terms of the shapes of deformed staple legs and plywood material crushed underneath staple legs taken at different loading levels: a $325.9 \mathrm{~N}$ below the mean value of the first proportional limit point, $F_{\text {pl-1; }} ; \mathbf{b} 616.9 \mathrm{~N}$ passing mean value of the first yield point, $F_{\mathrm{y}-1} ; \mathbf{c} 900.0 \mathrm{~N}$ below the mean value of the second proportional limit point, $F_{\mathrm{pl}-2} ; \mathbf{d} 1200 \mathrm{~N}$ passing the mean value of the second yield point, $F_{y-2} ; \mathbf{e} 1271 \mathrm{~N}$ before passing the mean value of the ultimate load point, $F_{u}$

In Stage 3, the lateral load started from the end of the second yield curve, gradually reached its ultimate point, $F_{u}$, and then decreased gradually. The mean lateral load at ultimate point (with its COV) of evaluated SPSCs was $1276 \mathrm{~N}(10.5 \%)$. In this stage, staple legs continued their one plastic hinge bending process, and plywood materials underneath staple legs in side member and above staple legs in main member continued its compressed-yielding process, and meanwhile staples started the process of withdrawing from the main member (Fig. 11e) before the lateral load passed the ultimate point.

\section{Linear model}

Figure 12 is the linear mechanical model of a single staple leg proposed to derive equations for prediction of lateral loads of SPSCs at the first proportional limit, $F_{\mathrm{pl}-1}$, and first yield point, $F_{\mathrm{y}-1}$, in Stage 1, including its free-body diagrams. The assumptions made for deriving the equation of the lateral load of SPSCs at the first proportional limit based on failure modes observed in Fig. 11a are that (1) compressed plywood materials above and underneath staple legs nearby the contacted sides of side and main members are in their elastic range because there was no obvious non-recoverable deformation observed at this stage; (2) the single staple leg-bearing unit load at point A (Fig. 12a), $q_{\mathrm{A}}$, reaches its first proportional limit value, $q_{\mathrm{pl}}$; (3) the staple leg in main member bends in its elastic range, just reaches its proportional limit value, $M_{\mathrm{p}}$, at point $B$ where the shear force is zero based on EYM [25], i.e., the distance between two points $A$ and $B$ is $x \mathrm{~mm}$, and

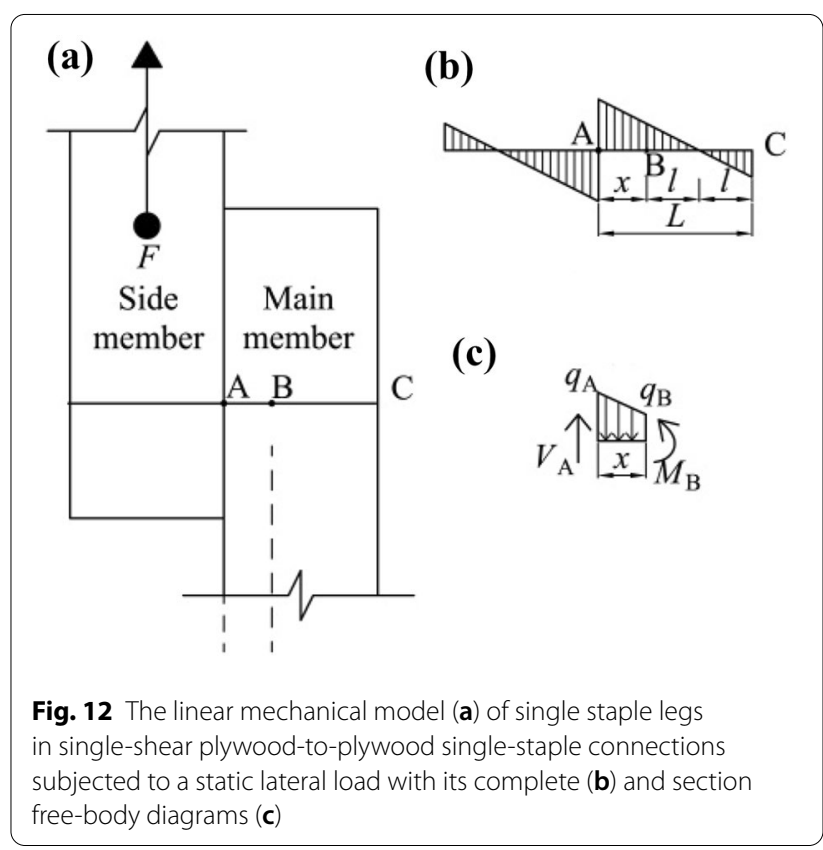

all forces act on the staple leg section $\mathrm{AB}$ remain in static equilibrium. While, the assumptions made for deriving the equation of the lateral load of SPSCs at the first yield point based on failure modes observed in Fig. 11b are that (1) plywood materials in compression above and below staple legs are still in its elastic range; (2) the single staple leg-bearing unit load at point $\mathrm{A}, q_{\mathrm{A}}$, just reached its yield load, $q_{y}$; (3) the single staple leg continues its 
bending process at point $\mathrm{B}$, where the shear force is zero [25], and all forces remain in static equilibrium.

Based on the geometric relationship of the linear mechanical model (Fig. 12b), the single staple leg-bearing unit load at point B (Fig. 12c), $q_{\mathrm{B}}$, can be derived as $\frac{L-x}{L+x} q_{\mathrm{A}}$, where $L$ is the length of a staple leg in main member and also the thickness of plywood. Summarizing all moments in the section free-body diagram (Fig. 12c) to zero at pivot point $\mathrm{A}$ yields the following moment equation (Eq. 4). Submitting $q_{\mathrm{B}}=\frac{L-x}{L+x} q_{\mathrm{A}}$ into Eq. (4) resulted the simplified equation (Eq. 5):

$$
\begin{aligned}
& M_{\mathrm{B}}-\left[\frac{\left(q_{\mathrm{B}}+q_{\mathrm{A}}\right) x}{2}\right]\left[\frac{\left(2 q_{\mathrm{B}}+q_{\mathrm{A}}\right) x}{3\left(q_{\mathrm{B}}+q_{\mathrm{A}}\right)}\right]=0, \\
& q_{\mathrm{A}} x^{3}-3 q_{\mathrm{A}} L x^{2}+6 M_{\mathrm{B}} x+6 M_{\mathrm{B}} L=0 .
\end{aligned}
$$

By setting $q_{\mathrm{A}}=q_{\mathrm{p}}, M_{\mathrm{B}}=M_{\mathrm{pl}}$ (Table 1$)$, and $L=18 \mathrm{~mm}$ (the length of a staple leg in main member which is equal to the thickness of six-ply southern yellow pine plywood) in Eq. (5), the $x$ value for deriving the estimation equation of the lateral load of SPSCs at the first proportional limit point can be calculated as $2.788 \mathrm{~mm}$ using MATLAB 7.0 software (MathWorks Inc., 2004).

Summarizing all forces in the vertical direction in the section free-body diagram (Fig. 12c) to zero yields the following vertical force equation (Eq. 6) for the calculation of the lateral load of single staple at point $\mathrm{A}, V_{\mathrm{A}}(\mathrm{N})$ in plywood main member:

$$
V_{\mathrm{A}}-\frac{\left(\frac{L-x}{L+x} q_{\mathrm{A}}+q_{\mathrm{A}}\right) x}{2}=0 .
$$

Therefore, the lateral load of SPSCs at the first proportional limit point, $F_{\mathrm{pl}-1}(\mathrm{~N})$, can be estimated using the following equation (Eq. 7) through setting $F_{\mathrm{pl}-1}=2 \quad V_{\mathrm{A}}$ because of two staple legs:

$$
F_{\mathrm{pl}-1}=\frac{2 L}{L+x} q_{\mathrm{A}} x .
$$

Setting $q_{\mathrm{A}}=q_{\mathrm{pl}}$ (Table 1$), L=18 \mathrm{~mm}$, and $x=2.788 \mathrm{~mm}$ in Eq. (7) resulted in the value of $347.1 \mathrm{~N}$ of the lateral load of SPSCs at the first proportional limit point.

The lateral load of SPSCs at the first yield point, $F_{\mathrm{y}-1}$, can be estimated as $413.7 \mathrm{~N}$ through setting $x=2.788 \mathrm{~mm}, q_{\mathrm{A}}=q_{\mathrm{y}}$, and $L=18 \mathrm{~mm}$ in Eq. (7), assuming that the staple leg was bent at the same location during its entire deformation process.

\section{Yield model}

Figure 13a is the mechanical yield model I of single staple legs in SPSCs proposed to derive equations for prediction of the lateral load of SPSCs at the second proportional

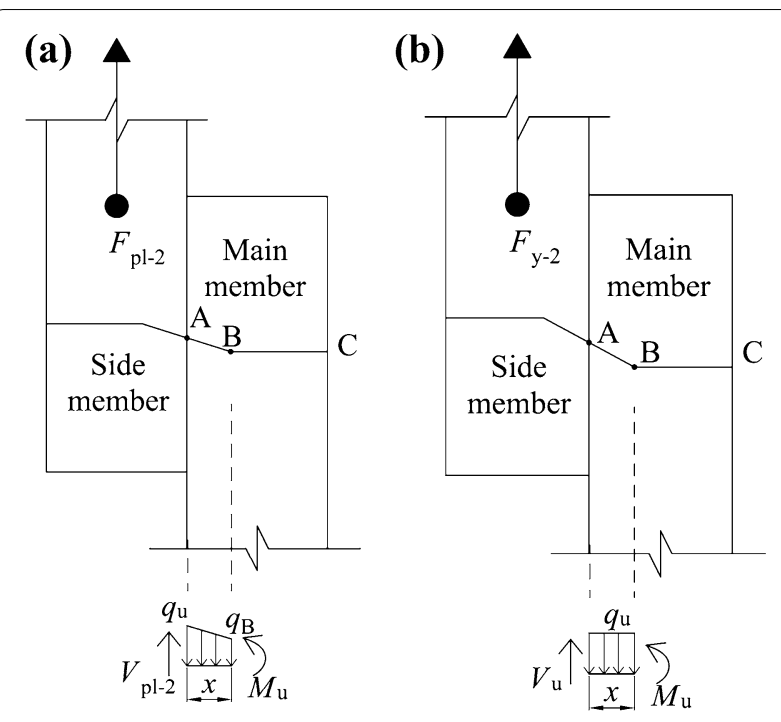

Fig. 13 Mechanical yield models I (a) and II (b) including their corresponding section free-body diagrams of single staple legs in single-shear plywood-to-plywood single-staple connections used to derive lateral loads $F_{\mathrm{pl}-2}$ and $F_{\mathrm{y}-2}$ in Stage 2, respectively

limit point, $F_{\mathrm{pl}-2}$, in Stage 2. The assumptions made based on failure modes observed in Fig. 11c are that (1) plywood materials in compression above and below staple legs are in its plastic range; (2) the staple leg-bearing unit load at point $\mathrm{A}, q_{\mathrm{A}}$, just reaches its ultimate value, $q_{\mathrm{u}}$; (3) single staple leg at point $\mathrm{B}$, reaches its ultimate bending moment, $M_{w}$, where the shear force is zero; (4) the value of $x$ equal to $2.788 \mathrm{~mm}$ estimated in the linear model; (5) all forces and moments on the section freebody diagram remain in static equilibrium.

The lateral load of SPSCs at the second proportional limit point can be estimated through starting the substitution of $q_{\mathrm{A}}=q_{\mathrm{u}}, M_{\mathrm{B}}=M_{\mathrm{u}}$ (Table 1), and $x=2.788 \mathrm{~mm}$ into Eq. (4) and resulting in the value of $105.5 \mathrm{~N} / \mathrm{mm}$ for the staple leg-bearing unit load at point $\mathrm{B}, q_{\mathrm{B}}$. Summarizing all forces in the vertical direction in the section freebody diagram (Fig. 13a) to zero, yielding the following vertical force equation (Eq. 8):

$$
V_{\mathrm{pl}-2}=\frac{\left(q_{\mathrm{u}}+q_{\mathrm{B}}\right) x}{2} .
$$

Therefore, the lateral load of SPSCs at the second proportional limit point, $F_{\mathrm{pl}-2}(\mathrm{~N})$, can be estimated using the following equation (Eq. 9) through setting $F_{\mathrm{pl}-2}=2 V_{\mathrm{pl}-2}$ :

$$
F_{\mathrm{pl}-2}=\left(q_{\mathrm{u}}+q_{\mathrm{B}}\right) x .
$$

Substituting $x=2.788 \mathrm{~mm}, q_{\mathrm{u}}=206.6 \mathrm{~N} / \mathrm{mm}$, and $q_{\mathrm{B}}=105.5 \mathrm{~N} / \mathrm{mm}$ into Eq. (9) yields the value of $871 \mathrm{~N}$ for 
the lateral load of SPSCs at the second proportional limit point.

Figure 13b shows the mechanical yield model II of single staple legs proposed to derive equations for predicting the lateral loads of SPSCs at the second yield load point, $F_{\mathrm{y}-2}$, in Stage 2. The assumptions made based on failure modes observed in Fig. 11d are that (1) compressed plywood materials above the staple leg nearby the contacted side of main member, $A B$ section, are in their plastic range; (2) the compressive single staple legbearing unit load reaches the ultimate load, $q_{\mathrm{u}}$; (3) the bending moment of single staple leg at its bending point $\mathrm{B}$ reaches its ultimate value, $M_{u}$; (4) the shear force at the conjunction point A reaches its ultimate value, $V_{\mathrm{u}}$ [25]; (5) the value of $x$ is equal to the one estimated in the linear model; (6) all forces and moments on the section free-body diagram remain in static equilibrium;

Summarizing all forces in the vertical direction in the section free-body diagram (Fig. 13b) to zero yields the following equation (Eq. 10) for prediction of the ultimate shear force at point $\mathrm{A}$ :

$$
V_{\mathrm{u}}=q_{\mathrm{u}} x .
$$

By setting $F_{\mathrm{y}-2}=2 V_{\mathrm{u}}$, the lateral load of SPSCs at the second yield load point can be estimated using the following equation (Eq. 11):

$$
F_{\mathrm{y}-2}=2 q_{\mathrm{u}} x .
$$

Substituting $q_{\mathrm{u}}=206.6 \mathrm{~N} / \mathrm{mm} \quad($ Table 1$)$ and $x=2.788 \mathrm{~mm}$ into Eq. (12) yields the value of $1152 \mathrm{~N}$ for the lateral load of SPSCs at the second yield point.

In Stage 3, as staple legs continued their one plastic hinge bending process and plywood materials above staple legs in main member continued their compressedyielding process the staple started its withdrawing process so called rope effect, i.e., picking up the lateral load SPSCs peaked because of staple leg bending moment reaching its ultimate value and staple leg-bearing unit load reaching its ultimate value. The contribution of rope effect on the increase of lateral loads for nails and staple is equal to $25 \%$ ultimate direct withdrawal $\left(f_{\mathrm{u}}\right)$ [30]. Therefore, the equation for predicting the ultimate lateral load of SPSCs can be derived as the following equation (Eq. 12):

$$
F_{\mathrm{u}}=F_{\mathrm{y}-2}+f_{\mathrm{u}} / 4
$$

Substituting $F_{\mathrm{y}-2}=1152 \mathrm{~N}$ and $f_{\mathrm{u}}=889.7 \mathrm{~N}$ (Table 2) into Eq. (12) yields the value of $1375 \mathrm{~N}$ for the estimated ultimate lateral load of SPSCs.

Table 2 summarizes predicted values of five critical lateral loads of SPSCs using prediction equations derived based on the proposed models in this study, and their corresponding observed values, and ratios of predicted to observed values. Ratio values ranging from 0.96 to 1.14 indicate that the derived prediction equations can estimate the critical lateral loads of SPSCs reasonably well.

However, the available equations (Eq. 13 [28] and Eq. 14 [29]) were used to predict the lateral loads of SPSCs at the ultimate load point, their ratios of predicted to observed values are 0.69 and 0.60 , respectively, which suggests that these two equations tend to underestimate the lateral loads of SPSC at ultimate load point:

$$
\begin{aligned}
& F_{\mathrm{u}-\text { Anue }}=2 * \sqrt{2 p_{\mathrm{u}} M_{\mathrm{y}}} \\
& F_{\mathrm{u}-\text { Eurocode }}=2 * 1.15 \sqrt{2 f_{\mathrm{em}, \mathrm{y}} d M_{\mathrm{y}}}+f_{\mathrm{u}} / 4
\end{aligned}
$$

\section{Conclusions}

The load-slip behavior of SPSCs was investigated. Experimental results concluded that:

(1) The load-slip behavior of SPSCs can be charac-

\begin{tabular}{|c|c|c|c|c|c|}
\hline Critical load & Model & Eq. & Observed (N) & Predicted $(\mathrm{N})$ & Ratio \\
\hline$F_{\mathrm{pl}-1}$ & Linear & $\frac{2 L}{L+x} q_{\mathrm{pl}} x$ & $329.8(12.9)$ & 347.1 & 1.05 \\
\hline$F_{y-1}$ & & $\frac{2 L}{L+x} q_{y} x$ & $363.4(12.5)$ & 413.7 & 1.14 \\
\hline$F_{\mathrm{pl}-2}$ & Yield I & $\left(q_{\mathrm{u}}+q_{\mathrm{B}}\right) x$ & $903.6(11.1)$ & 871 & 0.96 \\
\hline$F_{y-2}$ & Yield II & $2 q_{u} x$ & $1056(11.7)$ & 1152 & 1.09 \\
\hline \multirow[t]{3}{*}{$F_{\mathrm{u}}$} & Yield II & $2 q_{u} x+f_{u} / 4$ & $1276(10.5)$ & 1375 & 1.08 \\
\hline & Aune [28] & $2 \sqrt{2 q_{u} M_{y}}$ & & 764.6 & 0.60 \\
\hline & Eurocode 5 [29] & \multicolumn{2}{|c|}{$2 *\left(1.15 \sqrt{2 f_{e m, y} d M_{y}}\right)+f_{u} / 4$} & 874.2 & 0.69 \\
\hline
\end{tabular}
terized with three major stages, i.e., the load-slip curve of a SPSC started with its first linear and curved line section of Stage 1, followed by its sec-

Table 2 Comparisons of predicted and observed values at critical points

The values in parentheses are coefficient of variance 
ond linear and curved line section of Stage 2, and ended with a yielding curve of Stage 3.

(2) This experiment provided the evidence that the ultimate lateral load capacity of SPSCs was partially governed by staple direct withdrawal load capacity in main members.

(3) The derived equations for estimating lateral loads at critical points of SPSCs based on the proposed linear and mechanical yield models established using connection failure modes observed during its complete loading process were verified experimentally in this study.

Further validation is required if these derived equations are used for general applications in other woodbased composites such as oriented strand board, particleboards, wood-plastic composites, etc.

\begin{abstract}
Abbreviations
SPSC: Single-shear plywood-to-plywood single-staple connection; EYM: European Yield Model;; SG: Specific gravity; MC: Moisture content; COV: Coefficient of variance; $F_{\text {em }}$ : Single staple leg-bearing strengths in pine plywood; $F_{\text {em }}$ p. $F_{\mathrm{em}, y^{\prime}}$ and $F_{\mathrm{em}, \mathrm{u}}$ : Critical single staple leg-bearing strengths in pine plywood at proportional limit, yield point and ultimate point, respectively; $P$ : Compressive load; $w$ : Staple leg width; $L$ : Length of staple leg; $t$ : Thickness of a plywood block; q: Single staple leg-bearing unit loads; $q_{p}, q_{y^{\prime}}$ and $q_{u}$ : Critical single staple leg-bearing unit loads at proportional limit point, yield point and ultimate point, respectively; $M$ : Bending moment; $P_{\mathrm{b}}$ : Test bending load at each critical point; $S_{\mathrm{bp}}$ : Span; $F_{\mathrm{y}-1}$ : The yield load in the first linear-yield portion; $F_{\mathrm{pl-1}}$ : The first proportional limit load; $F_{\mathrm{y}-2}$ : The yield load at the second linear-yield portion; $F_{\mathrm{pl}-2}$ : The second proportional limit load; $F_{\mathrm{B}}$ : Ultimate load; $q_{\mathrm{A}}$ and $q_{\mathrm{B}}$ : Single staple leg-bearing unit load at point $A$ and $B$, respectively; $x$ : Distance between point $A$ and $B ; M_{B}$ : Bending moment at point $B ; M_{\mathrm{pl}}$ and $M_{4}$ : Bending moment of staple at proportional limit point and ultimate point, respectively; $V_{A}:$ Vertical force in plywood main member; $V_{L}$ : Shear force at the conjunction point $A$ reaches its ultimate value; $f_{u}$ : Ultimate direct withdrawal; FEM: Finite element method.
\end{abstract}

\section{Acknowledgements}

We would like to show our greatest thanks to Department of Sustainable Bioproducts of Mississippi State University (MSU) for providing us materials and equipment used in this study. Meanwhile, we also appreciate Mr. Franklin Quin, research assistant in MSU for his help during the experimental tests.

\section{Authors' contributions}

WH: methodology, software, formal analysis, investigation, data curation, writing original draft preparation, funding acquisition; JZ: conceptualization, methodology, resources, writing original draft preparation, review and editing. Both authors read and approved the final manuscript.

\section{Funding}

This work was partially supported by Scientific Research Foundation of Metasequoia Teacher (163104060), and Project from International Cooperation Joint Laboratory for Production, Education, Research and Application of Ecological Health Care on Home Furnishing.

Availability of data and materials

The data are available if needed.

\section{Declarations}

\section{Competing interests}

This manuscript has not been submitted to any of other journals, and the manuscript has not been published previously (partly or in full). Its publication is approved by all authors and tacitly or explicitly by the responsible authorities where the work was carried out. There is no conflict of interest in this manuscript.

\section{Author details}

${ }^{1}$ Co-Innovation Center of Efficient Processing and Utilization of Forest Resources, Nanjing Forestry University, Nanjing 210037, China. ${ }^{2}$ Department of Sustainable Bioproducts, Mississippi State University, P. O. Box 9680, Starkville, MS 39762-9820, USA. ${ }^{3}$ Department of Furniture Design, Nanjing Forestry University, Nanjing 210037, China.

Received: 14 February 2021 Accepted: 19 May 2021

Published online: 26 May 2021

\section{References}

1. Zhang T, Wu Z, Sun T (2019) Analyzing the influence of the ground layer on reinforcement strength of lacquer film in the restoration of ancient Chinese lacquer furniture. BioResources 14(1):431-439

2. Zhou C, Luo X, Huang T, Zhou T (2020) Function matching of terminal modules of intelligent furniture for elderly based on wireless sensor network. IEEE Access 8(13):2481-2488

3. Gu Y, Zhang J (2020) Tensile properties of natural and synthetic rattan strips used as furniture woven materials. Forests 11(12):1299

4. Liu X, Lv M, Liu M, Lv J (2019) Repeated humidity cycling's effect on physical properties of three kinds of wood-based panels. BioResources 14(4):9444-9453

5. Wang W, Peng J, Zhao Z, Zhou X, Zhang J, Du G (2020) Modification of melamine-formaldehyde resin for decoration board. J Forest Eng 5(2):42-47

6. Zhao Z, Sun S, Wu D, Zhang M, Huang C, Umemura K, Yong Q (2019) Synthesis and characterization of sucrose and ammonium dihydrogen phosphate (SADP) adhesive for plywood. Polymers 11:1909

7. Fu W, Guan H, Zhang X (2021) Verification and further study on method of measuring contact force between mortise and tenon joint. BioResources 16(1):263-276

8. Xi X, Yang Y, Zhang Z (2020) Pull-out force and finite element analysis of T-shaped components of Vitex negundo L. scrimber with different node forms. J Forest Eng 5(1):182-187

9. Chen Y, Zhu J (2019) Study on bending characteristics of fast growing eucalyptus bookcase shelves by using burgers model. Wood Res-Slovakia 64(1):137-144

10. Chen Y, Wu Z (2018) Study on structure optimization design of modified wood furniture tenon structure based on the finite element analysis of ANSYS. J Intell Fuzzy Syst 34(2):913-922

11. Wu G, Sun J, Huang C, Ren H, Zhao R (2020) Research progress on mechanical properties of tenon-mortise joints in traditional Chinese wood structures. J Forest Eng 5(4):29-37

12. Chen $Y$, Yang $Y$, Zhang $Z$ (2019) Study on small-diameter wood scrimber and furniture design. J Forest Eng 4(1):155-159

13. Zhou Z, Li X, Ding J, Guo X, Cao P (2019) Structure design and process analysis of internal heating engineered wood flooring. J Forest Eng 4(1):165-169

14. Zhang J, Quin F, Tackett B, Park S (2002) Direct withdrawal strength of single-staple joints in pine plywood. Forest Prod J 52(2):86-91

15. Zhang J, Quin F, Tackett B (2002) Direct withdrawal strength of multistaple joints in pine plywood. Forest Prod J 52(5):61-66

16. Zhang J, Maupin M (2004) Face lateral and withdrawal resistances of staple joints in furniture-grade pine-plywood. Forest Prod J 54(6):40-46

17. Yadama V, Syed BM, Steele PH, Lyon DE (1991) Effects of leg penetration on the strength of staple joints in selected wood and wood-based materials. Forest Prod J 41(6):15-20 
18. Yadama V, Zhang J, Syed B, Steele P (2002) Experimental analysis of multiple staple joints in selected wood and wood-based materials. J Test Eval 30(5):400-407

19. Demirel S, Zhang J, Jones D, Kitchens S, Martin W, Yu H (2013) Face lateral shear resistance of one-row multistaple joints in oriented strandboard. Forest Prod J 3(5/6):207-212

20. Demirel S, Zhang J (2014) Face lateral resistance of oriented strandboard joints connected with two rows of 16-gauge coated staples. Wood Fiber Sci 46(2):280-290

21. Demirel S, Kalayci G (2020) Measuring and estimating shear force of one stapled and one row multi stapled wood joints. Maderas Cien tecnol 22(3):395-404

22. Erdil YZ, Zhang J, Eckelman CA (2003) Staple holding strength of furniture frame joints constructed of plywood and oriented strandboard. For Prod J 53(1):70-75

23. Genchev Y, Staneva N, Hristodorova D (2016) Comparative analysis of bending strength of end to face butt staple joints by FEM. Chip Chipless Woodworking Process 10(1):37-42

24. Staneva N, Genchev Y, Hristodorova D (2016) Analysis of deformation behavior of staple corner joint for upholstered furniture by FEM. In: 27th International Conference on Wood Science and Technology "Implementation of Wood Science in Woodworking Section", 13th-14th of Oct, Zagreb, Croatia, pp. 67-73

25. Johansen KW (1949) Theory of timber connections. International Association of Bridge and Structure Engineering Publications 9, Bern, 9:249-329

26. Kretschmann DE (2010) Wood handbook-Wood as an engineering material, Forest Products Laboratory, General Technical Report FPL-GTR-190, United States Department of Agriculture, Forest Service, Madison, pp. 508
27. Eshaghi S (2013) Investigation on lateral resistance of joint made with dry wall and sheet metal screws in bagasse particleboard and comparison with that of commercial MDF. Maderas Cien technol 15(2):127-140

28. Aune P, Malloty MP (1986) Lateral load-bearing capacity of nailed joints based on the yield theory: experimental verification. United States Department of Agriculture, Research paper FPL, pp. 470

29. EN 1995-1-1 (2004) Eurocode 5: design of timber structure-part 1-1: General-Common rules and rules for buildings (English version), European Committee for Standardisation

30. ASTM D5764-97 (2018) Standard test method for evaluating dowelbearing strength of wood and wood-based products, American Society for Testing Materials, West Conshohocken, PA

31. ASTM F1575-17 (2017) Standard test method for determining bending yield moment of nails, American Society for Testing Materials, West Conshohocken, PA

32. ASTM D2395-93 (2017) Standard test methods for specific gravity of wood and wood-based materials, American Society for Testing Materials, West Conshohocken, PA

33. ASTM D4442-92 (2013) Standard test methods for direct moisture content measurements of wood and wood-based materials, American Society for Testing Materials, West Conshohocken, PA

34. ASTM D1761 (2010) Standard test methods for mechanical fasteners in wood, American Society for Testing Materials, West Conshohocken, PA

\section{Publisher's Note}

Springer Nature remains neutral with regard to jurisdictional claims in published maps and institutional affiliations.

\section{Submit your manuscript to a SpringerOpen ${ }^{\odot}$ journal and benefit from:}

- Convenient online submission

- Rigorous peer review

- Open access: articles freely available online

- High visibility within the field

- Retaining the copyright to your article

Submit your next manuscript at springeropen.com 